\title{
Article \\ Effect of Different Kefir Source on Fermentation, Aerobic Sta- bility, and Microbial Community of Alfalfa Silage
}

\author{
Fisun Koç ${ }^{1}$, Emel Özkan Ünal ${ }^{1}$, Berrin Okuyucu ${ }^{1}$, Selim Esen ${ }^{2, *}$ and Raziye Işık ${ }^{3}$
}

1 Department of Animal Science, Tekirdag Namık Kemal University, 59030 Tekirdag, Turkey; fkoc@nku.edu.tr 2 Balikesir Directorate of Provincial Agriculture and Forestry, Republic of Turkey Ministry of Agriculture and Forestry, Manyas, 10470 Balikesir, Turkey; selim_esen01@hotmail.com

3 Department of Agricultural Biotechnology, Tekirdag Namık Kemal University, 59030 Tekirdag, Turkey; risik@nku.edu.tr

* Correspondence: selim_esen01@hotmail.com

\begin{abstract}
Simple Summary: Minimizing the silage additives cost while increasing silage quality is important for a sustainable livestock enterprise especially in undeveloped and developing countries. In this study, therefore, commercially available kefir yeast (CK) and homemade kefir culture (HK), as a low-cost additive, was applied at four different application doses (untreated control, 5.0, 5.7, and $6.0 \log$ cfu $\mathrm{g}^{-1}$ ) on wilted alfalfa and evaluated with the fermentation characteristics and aerobic stability. The addition of CK with an application dose of $5.0 \log \mathrm{cfu} \mathrm{g}^{-1}$ and HK with an application dose greater than $5.0 \mathrm{log} \mathrm{cfu} \mathrm{g}^{-1}$ prevent mould formation and inhibit yeast counts in silages. Indeed, both CK and HK improve the silage quality and aerobic stability of alfalfa even with low water-soluble carbohydrate content.
\end{abstract}

\begin{abstract}
The present study has been one of the first attempts to thoroughly examine the effects of different kefir sources on fermentation characteristics, aerobic stability, and microbial communities of alfalfa silages. The effects of commercial kefir (CK) and homemade kefir culture (HK) applied with four different application doses (untreated control (CON), 5.0, 5.7, and $6.0 \log \mathrm{cfu} \mathrm{g}^{-1}$ ) on wilted alfalfa and stored at an ambient temperature of $25-30{ }^{\circ} \mathrm{C}$. After 45 days ensiling, fermentation characteristics and aerobic stability of silages were measured and bacterial diversity was investigated by $16 \mathrm{~S}$ ribosomal RNA gene sequencing using GenomeLab ${ }^{\mathrm{TM}} \mathrm{GeXP}$ platform. Both CK and $\mathrm{HK}$ accelerate more lactic acid production and reduced ammonia nitrogen concentration. Factor analysis of kefir sources suggest that the addition of kefir improves the aerobic stability of silages even the initial water soluble carbohydrate (WSC) content is inadequate via its antimicrobial effect on yeast and mould formation. Enterococcus faecium, Pediococcus pentosaceous, and Lactobacillus brevis were dominant bacterial species among the treated groups at silo opening while Lactobacillus plantarum and Lactobacillus brevis became dominant bacterial species after 7 days of aerobic exposure. In conclusion, application of kefir on alfalfa silages improves fermentation quality and aerobic stability even with low WSC content.
\end{abstract}

Keywords: kefir, alfalfa, silage, fermentation quality, microbial communities

\section{Introduction}

Alfalfa (Medicago sativa L.), one of the most common perennial forage legumes, plays a pivotal role in meeting the nutritional requirements of ruminants worldwide. It is mainly associated with high protein content and high nutritional quality, yielding high dry matter per acre and broader adaptation capability [1]. The most well-known application to minimize nutrient losses for future use of fresh forage crops is ensiling. Nevertheless, the main challenge faced by many researchers at ensiling process is the high buffering capacity (Bc) and low concentration of water-soluble carbohydrates (WSC), and high moisture content of alfalfa which results in undesirable secondary clostridial fermentation [2]. In such cases, the use of inhibitors or inoculants becomes mandatory to 
dominate microbial biota by lactic acid bacteria (LAB), which fermented the lysed plant membranes to lactic acid resulting in a lower $\mathrm{pH}$ of the ensiled material [3].

Commercial LAB has been used for many years as microbial additives owing to their inhibitory effect on undesirable microorganisms, e.g., Clostridia, Enterobacter, and several other bacteria [4]. It is also well known from previous studies that LAB has a favorable contribution to the quality of the silage in terms of flavor and sensory profile, and preservation time of the final products $[5,6]$. However, as previously stated by Tao et al. [7], adding commercial LAB is one of the most frequently stated problems due to its high cost, especially in undeveloped and developing countries. Schnürer and Jonsson [8] were obviously right to draw our attention to the ingredients of an excellent starter culture for well-preserved silage recommending a combination form of yeast and LAB; hence, kefir might be used as an alternative silage additive due to its complex symbiotic diversity of microorganisms which shown heterofermentative properties including LAB, yeast, and acetic acid bacteria [9]. There is a notable lack of high-quality research focusing specifically on fermentation characteristics, aerobic stability, and microbial community of alfalfa silages inoculated with different kefir sources.

In this study, commercial and homemade kefir was applied at three different rates onto first-cut alfalfa and evaluated with the fermentation characteristics and aerobic stability. The microbial community was determined by high-throughput sequencing methods after ensiling and aerobic exposure (AE) to explain the impact of isolated bacteria from alfalfa silages.

\section{Materials and Methods}

\subsection{Forage and Silage Preparation}

The plant material of the current study, alfalfa, was grown in an experimental plot of the Field Crops Department of Namık Kemal University $\left(40.59^{\circ} \mathrm{N}\right.$ and $27.34^{\circ} \mathrm{S}$, Tekirdag, Turkey). The total precipitation, long-term mean precipitation, mean average temperature, and long-term mean average temperature of the experimental year were 299.0 and $581.5 \mathrm{~mm}, 15.7$ and $14.0^{\circ} \mathrm{C}$, respectively. Since the total precipitation was not sufficient, forage water demands were supplied by irrigation fortnightly. First-cut alfalfa was harvested at the early blooming stage (10-20\%) on May 18, 2019, by a forage harvester, wilted for $24 \mathrm{~h}$, and manually chopped to approximately $1.5-2.0 \mathrm{~cm}$ in length. Wilted alfalfa had a $304.6 \mathrm{~g} \mathrm{~kg}^{-1}$ dry matter (DM), $202.1 \mathrm{~g} \mathrm{~kg}^{-1} \mathrm{DM}$ of crude protein (CP), $15.45 \mathrm{~g}$ $\mathrm{kg}^{-1} \mathrm{DM}$ of WSC, 445 meqNAOH$/ \mathrm{kg} \mathrm{DM}$ of Bc, 7.50 of $\mathrm{pH}, 5.30 \log \mathrm{cfu} \mathrm{g}^{-1}$ of LAB, and $8.08 \mathrm{log} \mathrm{cfu}^{-1}$ of yeast and no mould before ensiling.

The silage was made laboratory-scale fermentation system: approximately $500 \mathrm{~g}$ wilted alfalfa was weighed and packed into polythene bags and then sealed by a vacuum sealer (CAS CVP-260PD). A commercial kefir yeast (MYStarter KF, contains Lactococcus lactis subsp. lactis biovar diacetylactis, Lactobacillus brevis, Leuconostoc mesenteroides subsp. mesenteroides ve Saccharomyces cerevisiae strains) and homemade kefir culture (contains Enterococcus faecalis, Lactobacillus brevis and Micrococcus luteus according to the 16S rRNA gene sequencing) was used for comparison. The silage treatments (each, 10 replicates) were designed as commercial kefir yeast (CF), and homemade kefir culture (HK) with four different application doses (untreated control (CON), 5.0, 5.7, and $6.0 \log \mathrm{cfu} \mathrm{g}^{-1}$ of fresh matter) for $45 \mathrm{~d}$ of ensiling at an ambient temperature of $25-30^{\circ} \mathrm{C}$.

\subsection{Chemical Analysis}

After $45 \mathrm{~d}$ of ensiling, opened silos subsampled for microbial enumeration and aerobic stability determination. A representative $20 \mathrm{~g}$ wet silage or pre-ensiled material was taken and gently mixed in $180 \mathrm{ml}$ of distilled water at room temperature for $1 \mathrm{~h}$ and then filtered through 4 layers of cheese-cloths to determine ammonia nitrogen $\left(\mathrm{NH}_{3}-\mathrm{N}\right)$ and organic acid content. The $\mathrm{pH}$ of each silo was measured using silage extract with a $\mathrm{pH}$ meter (WTW-inoLab ph 730). The DM of samples was determined by drying at $60 \pm 2$ ${ }^{\circ} \mathrm{C}$ in an air-forced oven for $48 \mathrm{~h}$, and DM loss was calculated via the weight differences 
between wilted alfalfa and opened silage samples. The nitrogen $(\mathrm{N})$ content of wilted alfalfa was measured by the Kjeldahl method and multiplied by 6.25 to get the crude protein $(\mathrm{CP})$ ratio by using AOAC methods. Samples were analyzed for $\mathrm{NH}_{3}-\mathrm{N}$ and WSC as previously reported by Anonymous [10] by using micro distillation and $0.2 \%$ anthrone reagent, respectively. The Bc of pre-ensiled alfalfa was determined by Playne and Mc Donald [11].

The organic acid content of silages (Acetic acid, AA; Propionic acid, PA; Butyric acid, BA) was evaluated after deproteinization of silage extract with the metaphosphoric acid-formic acid mixture (3:1, v:v) according to the procedure described by Ulger et al. [12] by using a gas chromatograph (Shimadzu GC-2010+, Kyoto, Japan) with a capillary column (Restek, Bellefonte, PA, USA; $30 \mathrm{~m}$, i. d.: $0,25 \mathrm{~mm}$, f.t.: 0,25 $\mu \mathrm{m}$ ), and with flame ionization detector (FID) over a temperature range of $45-230{ }^{\circ} \mathrm{C}$. The lactic acid (LA) content of silages was determined using a spectrophotometric method previously described by Koc and Coskuntuna [13].

\subsection{Microbial Populations}

The LAB, yeast, and mould count was performed by using subsamples immediately after opening the silos and after the $7 \mathrm{~d} \mathrm{AE}$ according to described previously by Seale et al. [14]. While the pour plate method and MRS Agar (Merck, Darmstadt, Germany) were used to determine $\mathrm{LAB}$ for incubating anaerobically at $30^{\circ} \mathrm{C}$ for $3 \mathrm{~d}$, the spread-plate method and potato dextrose agar (Merck, Darmstadt, Germany) were used yeast and mould enumeration after incubating aerobically at $30^{\circ} \mathrm{C}$ for $7 \mathrm{~d}$.

\subsection{Aerobic Stability Analysis}

Based on trapping $\mathrm{CO}_{2}$ gases into the $\mathrm{KOH}$ solution, the bottle system is one of the most common procedures for determining aerobic stability when reaching thermocouples is difficult. Generally, after 5 to 7 day of $\mathrm{AE}, \mathrm{pH}, \mathrm{CO}_{2}, \mathrm{LAB}$, yeast, and mould content of silage are used to assess aerobic stability. In the current study, both the bottle system, previously described by Asbell and Stenson [15] and thermocouples (HOBO Pendant Temperature/Light 64K Data Logger, Onset Computer Corporation, Bourne, MA, USA) was used to record temperature with a $2 \mathrm{~h}$ interval during the $7 \mathrm{~d}$ of AE. Aerobic deterioration was considered when the temperature of the silage samples is $2^{\circ} \mathrm{C}$ higher than the ambient temperature.

\subsection{Microbial Diversity Analysis}

After the proliferation of LAB in nutrient broth for $16 \mathrm{~h}, 1000 \mu \mathrm{l}$ of aliquot was taken and centrifuged at $1000 \mathrm{~g}$ for $10 \mathrm{~min}$. Microbial DNA from each silage sample was extracted after opening the silos and after the $7 \mathrm{~d}$ AE according to Liu et al. [16]. 16S rDNA regions were amplified using primers F: 5'-AGAGTTTGATCCCTGGCTCAG-3' and R: 5'-CCGTCAATTCCTTTGAGTTT-3' [17]. PCR amplification reactions; $50 \mu \mathrm{L}$ PCR volumes included: $10 \mathrm{ng}$ rDNA, $1 \mu \mathrm{M}$ of each primer, $1 \times$ PCR Buffer ((NH4)2SO4), $200 \mu \mathrm{M}$ dNTP, $2.0 \mathrm{mM} \mathrm{MgCl} 2$ and 0.1U i-Taq ${ }^{\mathrm{TM}}$ DNA polymerase $(5 \mathrm{U} / \mathrm{ml})$ (iNtRON Biotechnology Inc., US). The cycling protocol was $5 \mathrm{~min}$ at $95^{\circ} \mathrm{C}$ for initial denaturation, 37 cycles of amplification; $95^{\circ} \mathrm{C}$ for $45 \mathrm{~s}, 60^{\circ} \mathrm{C}$ annealings for $60 \mathrm{~s}, 72^{\circ} \mathrm{C}$ for the $40 \mathrm{~s}$ and $10 \mathrm{~min}$ at $72^{\circ} \mathrm{C}$ for final extension (Applied Biosystems ProFlex PCR System (Applied Biosystems, Foster City, CA USA)). Afterward, the PCR products were run on $1.0 \%$ agarose gel using horizontal electrophoresis, and the gels were stained with SafeView ${ }^{\mathrm{TM}}$ Classic (Applied Biological Material Inc. Canada). PCR products were visualized under UV light in the Gel Documentation System.

The PCR products were sequenced using GenomeLab ${ }^{\text {TM }}$ GeXP Genetic Analysis System (Beckman Coulter, Inc. Fullerton, CA, USA) after the precipitation with 3M NaAc. The chromatogram carefully checked the sequencing of the 16S rDNA region for overlapping nucleotide peaks by using ChromasPro Version 2.1.8 (Technelysium Pty. Ltd. Australia). The checked sequences file consisting of MSTN fragments were controlled by the MEGA7 software (Molecular Evolutionary Genetics Analysis, version 7.0 
[18]. The sequence data reported in this study were archived in The National Center for Biotechnology Information (NCBI) with the accession numbers MZ014989- MZ015001. The nucleotide sequences of studied $16 \mathrm{~S}$ rDNA region in different species were performed from The National Center for Biotechnology Information webpage (https://www.ncbi.nlm.nih.gov/). The retrieved partial sequences were aligned by Clustal $\mathrm{X}$ and phylogenetic tree was generated by the Neighbour Joining (NJ) method (Kimura 2) in MEGA 7 software [18].

\subsection{Statistical Analysis}

Data were previously adjusted for the fixed effects of additive (CK and HK), dose (no additive, 5.0, 5.7, and $6.0 \log$ cfu-1), and the interaction between these effects. This adjustment was made by analysis of variance using procedure PROC MIXED from SAS [19], considering the following statistical model:

$$
Y i j k=\mu+a i+b j+(a b) i j+e i j k
$$

in which, Yijk is the value of measured characteristics; $\mu$ is a constant associated with each observation; ai is the effect of additive $i$; $b j$ is the effect of dose $j$; (ab)ij is the interaction effect between the additive $i$ and dose $j$; eijk is the random error of each observation. The differences among treatment means were tested using Tukey's multiple range test, and significance was established at $\mathrm{P}<0.05$. Principal component analysis (PCA) was carried out according to the PRIN method of SAS by using the 19 variables and 1 supplementary variable (treatment group) and only PCAs with eigenvalues higher than 1 were retained and interpreted [19]. Furthermore, obtained PCAs were rotated orthogonal Varimax rotation by FACTOR procedure of SAS, and only with an absolute loading value higher than 0.50 were considered to load on specific extracted PCAs (SAS, 2004).

\section{Results}

Kefir sources and their application doses did not change the DM, and WSC content of the silages (Table 1). However, comparing the $\mathrm{pH}$ and DM loss data reveals that both kefir source and doses significantly affect $\mathrm{pH}(\mathrm{P}<0.05)$, and the DM loss values $(\mathrm{P}<0.001)$ of silages. The control and HK with an application dose of $6.0 \mathrm{log}$ cfu $\mathrm{g}^{-1}$ presented higher DM loss.

From the data in Figure 2, it is apparent that the LA and BA concentration of kefir sources and their different application doses significantly affected $(\mathrm{P}<0.001$ and $\mathrm{P}<0.05$, respectively) while the AA and PA did not ( $P>0.05)$. What stands out in this figure is the highest LA/AA ratio observed in the HK group with an application dose of $6.0 \mathrm{log}$ cfu $\mathrm{g}-1$, the lowest ratio observed in control. The results, as shown in Figure 2, also indicate that no statistically significant differences between the kefir sources and their application doses.

Table 1. Some chemical properties of alfalfa silage treated with different kefir source after $45 \mathrm{~d}$ of ensiling.

\begin{tabular}{|c|c|c|c|c|c|c|c|c|c|}
\hline \multirow{2}{*}{ Item } & \multirow{2}{*}{ Con } & \multicolumn{3}{|c|}{ CK $\left(\log\right.$ cfu g $\left.{ }^{-1}\right)$} & \multicolumn{3}{|c|}{ HK $\left(\log\right.$ cfu g $\left.^{-1}\right)$} & \multirow{2}{*}{ SEM } & \multirow{2}{*}{ P-value } \\
\hline & & 5.0 & 5.7 & 6.0 & 5.0 & 5.7 & 6.0 & & \\
\hline $\mathrm{DM}$ & 284.5 & 305.2 & 292.3 & 299.4 & 272.5 & 279.5 & 315.4 & 9.54 & 0.151 \\
\hline $\begin{array}{l}\mathrm{DM} \\
\text { loss }\end{array}$ & $26.2 \mathrm{a}$ & $26.2 \mathrm{a}$ & 21.0c & $23.1 b$ & $20.9 c$ & $25.6 a$ & $26.4 \mathrm{a}$ & 0.21 & $<0.001$ \\
\hline $\mathrm{pH}$ & $5.60 \mathrm{ab}$ & $5.70 \mathrm{ab}$ & $5.85 \mathrm{ab}$ & $5.50 \mathrm{ab}$ & $5.90 a$ & $5.45 b$ & $5.55 \mathrm{ab}$ & 0.08 & 0.024 \\
\hline WSC & 8.00 & 6.62 & 11.68 & 7.67 & 8.90 & 11.30 & 7.92 & 1.05 & 0.607 \\
\hline
\end{tabular}

DM: dry matter $\left(\mathrm{g} \mathrm{kg}^{-1}\right)$, WSC: water soluble carbohydrate $\left(\mathrm{g} \mathrm{kg}^{-1} \mathrm{DM}\right)$, cfu: colony-forming units, SEM: standard error of mean 

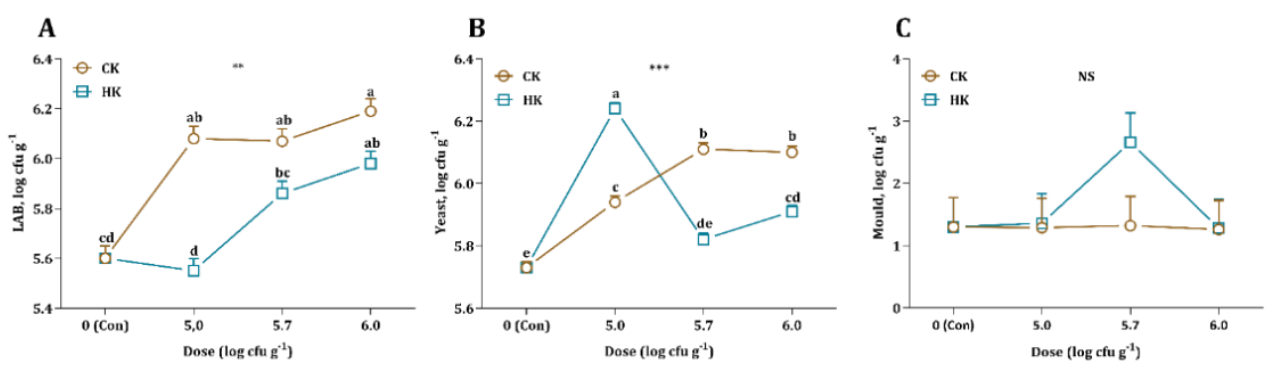

Figure 1. Microbiological composition of alfalfa silage after $45 \mathrm{~d}$ of ensiling

CK: commercial kefir, HK, homemade kefir, LAB: lactic acid bacteria. The values with different letters $(a, b, c, d)$ in each graph are statistically different $(P<0.05)$, NS: Not Significant, ${ }^{*} P<0.05,{ }^{* * *}$ : $\mathrm{P}<0.001$.
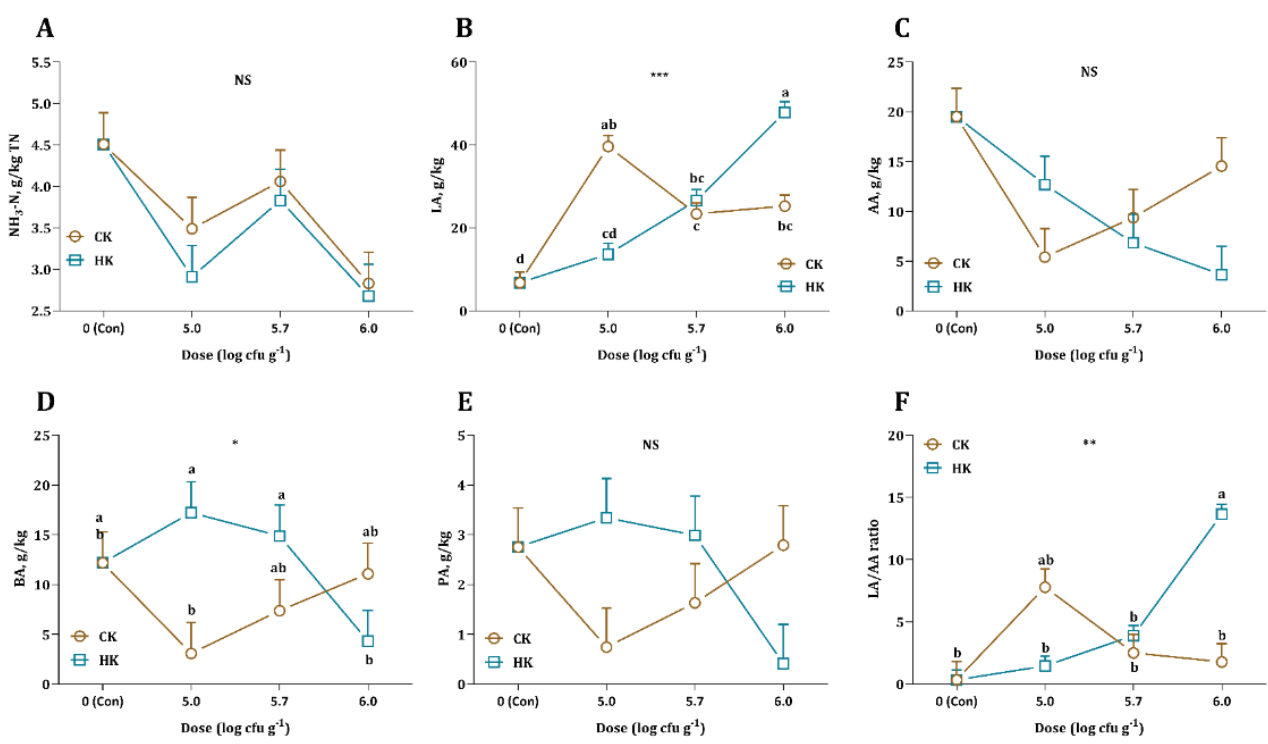

Figure 2. Fermentation characteristics of alfalfa silages after $45 \mathrm{~d}$ of ensiling.

CK: commercial kefir, $\mathrm{HK}$, homemade kefir, $\mathrm{NH}_{3}-\mathrm{N}$ : ammonia nitrogen, AA: acetic acid, BA: butyric acid, PA: propionic acid, LA: lactic acid. The values with different letters $(a, b, c, d)$ in each graph are statistically different $(\mathrm{P}<0.05), \mathrm{NS}$ : Not Significant, ${ }^{*}: \mathrm{P}<0.05,{ }^{* *}$ : $\mathrm{P}<0.001$.

The $\mathrm{DM}, \mathrm{pH}$, and $\mathrm{CO}_{2}$ values were similar among the kefir sources and their application doses, and no significant differences were observed up to $7 \mathrm{~d}$ of $\mathrm{AE}$ (Figure 3). On the other hand, the differences between the kefir sources and their application doses were significant for yeast $(\mathrm{P}<0.05)$ and mould $(\mathrm{P}<0.001)$. What is interesting about the data in this figure is that the CK with an application dose of 5.0 to $5.7 \mathrm{log}$ cfu g ${ }^{-1}$ and the HK with an application dose of higher than $5.0 \mathrm{log}_{\mathrm{cfu} \mathrm{g}} \mathrm{g}^{-1}$ prevents mould formation. Furthermore, a comparison of the data recorded by data logger reveals that the highest aerobic stability was observed in CK with an application rate of $5.7 \log$ cfu g-1 as $>168 \mathrm{~h}^{-1}$ wile the lowest observed in HK with an application $5.0 \mathrm{log} \mathrm{cfu} \mathrm{g}^{-1}$ as $32 \mathrm{~h}$ (Figure 3). 

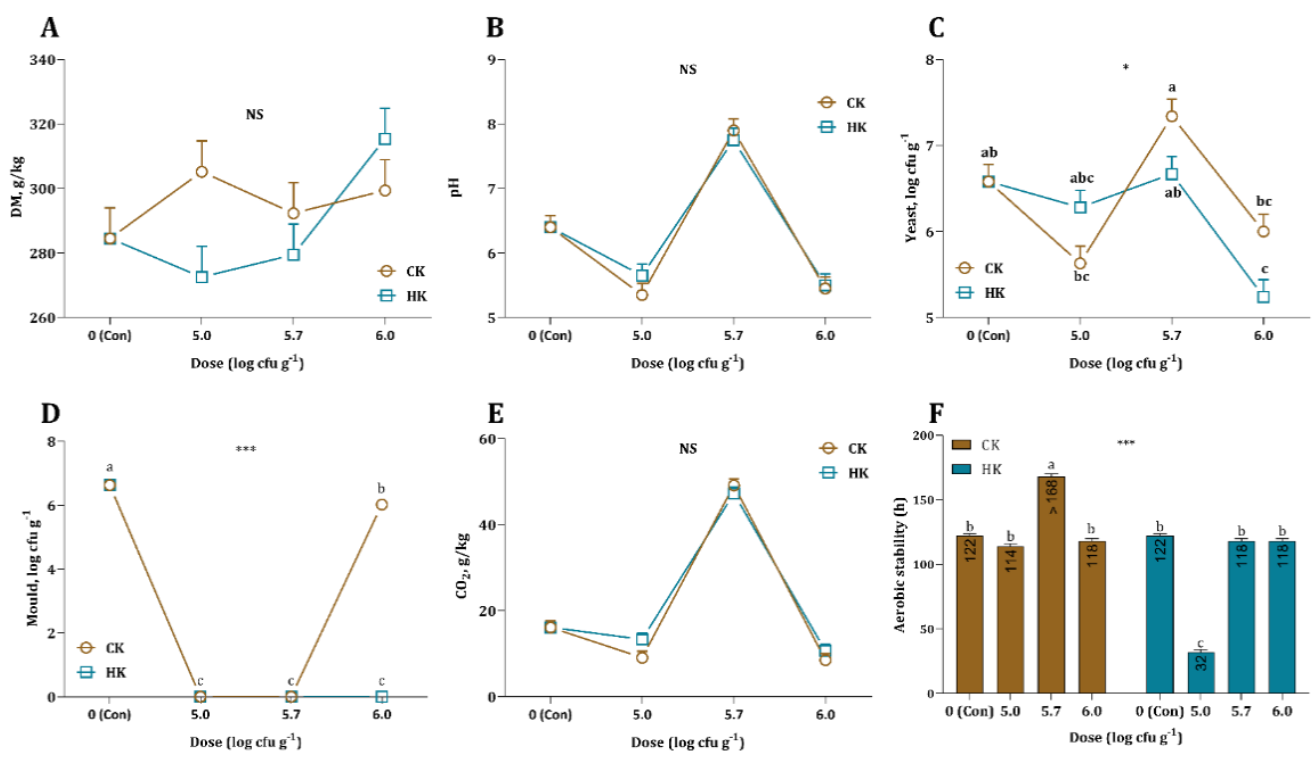

Figure 3. Aerobic stability profile of alfalfa silages after $7 \mathrm{~d}$ of aerobic exposure

$\mathrm{CK}$ : commercial kefir, $\mathrm{HK}$, homemade kefir, DM: dry matter, $\mathrm{CO}_{2}$ : carbon dioxide. The values with different letters $(a, b, c, d)$ in each graph are statistically different $(\mathrm{P}<0.05)$, NS: Not Significant, ${ }^{*}$ : $\mathrm{P}<0.05,{ }^{* * *}: \mathrm{P}<0.001$.

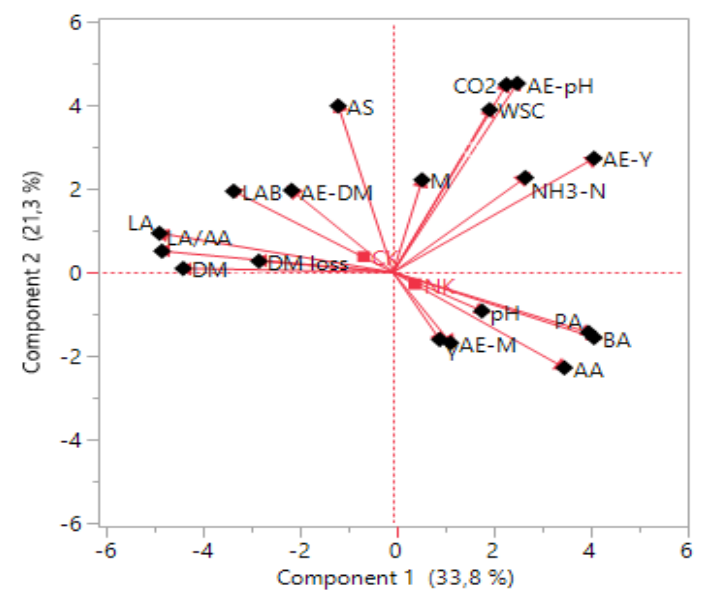

Figure 4. Biplot ordering using principal component analysis of alfalfa silage characteristics inoculated with different kefir sources.

CK: commercial kefir, HK, homemade kefir, DM: dry matter, DM loss: dry matter loss, WSC: water-soluble carbohydrate, NH3-N: ammonia nitrogen, AA: acetic acid, BA: butyric acid, PA: propionic acid, LA: lactic acid, CO2: carbon dioxide, AE: aerobic exposure, AS: aerobic stability, Y: yeast, M: mould, LAB: lactic acid bacteria.

Particularly revealing is how principal factor analysis explains $86.75 \%$ of the total variability of original variables (Table 2). Loading vectors associated with the original variables, with eigenvalues higher than 1 , are reported and used to interpret the meanings of 5 retained PCs. Biplot ordering using PCA of alfalfa silage characteristics inoculated with different kefir sources are also presented in Figure 4.

Table 2. Loading vectors of original variables after $45 \mathrm{~d}$ of ensiling alfalfa treated with different kefir source ${ }^{1}$ 


\begin{tabular}{|c|c|c|c|c|c|}
\hline Yeast (after aerobic exposure) & $0.780^{*}$ & $0.514^{*}$ & -0.050 & 0.231 & -0.030 \\
\hline Butyric acid & $0.780^{*}$ & -0.294 & 0.023 & -0.180 & 0.276 \\
\hline Propionic acid & $0.759^{*}$ & -0.271 & 0.120 & 0.003 & 0.382 \\
\hline Acetic acid & $0.665^{*}$ & -0.430 & 0.429 & 0.272 & 0.077 \\
\hline Ammonia nitrogen & $0.513^{*}$ & 0.427 & 0.446 & 0.049 & $-0.547^{*}$ \\
\hline $\mathrm{pH}$ & 0.345 & -0.174 & $-0.626^{*}$ & 0.262 & $-0.538^{*}$ \\
\hline pH (after aerobic exposure) & 0.482 & $0.851^{*}$ & -0.016 & -0.053 & -0.007 \\
\hline Carbon dioxide & 0.440 & $0.846^{*}$ & -0.156 & -0.091 & 0.051 \\
\hline Aerobic stability & -0.213 & $0.750^{*}$ & 0.340 & 0.447 & -0.061 \\
\hline Water soluble carbohydrate & 0.375 & $0.733^{*}$ & -0.288 & -0.067 & 0.240 \\
\hline Mould & 0.113 & 0.416 & 0.010 & $-0.630^{*}$ & 0.366 \\
\hline Mould (after aerobic exposure) & 0.223 & -0.318 & $0.751^{*}$ & 0.410 & 0.212 \\
\hline Dry matter loss & $-0.521^{*}$ & 0.050 & $0.693^{*}$ & -0.423 & -0.145 \\
\hline Lactic acid bacteria & $-0.619^{*}$ & 0.366 & -0.088 & $0.507^{*}$ & 0.281 \\
\hline Dry matter (after aerob & & & & & \\
\hline exposure) & -0.394 & 0.369 & 0.228 & 0.447 & 0.196 \\
\hline Yeast & 0.181 & -0.303 & $-0.826^{*}$ & 0.335 & 0.197 \\
\hline Lactic acid/Acetic acid & $-0.897^{*}$ & 0.095 & -0.151 & -0.218 & -0.037 \\
\hline Lactic acid & $-0.907^{*}$ & 0.176 & -0.206 & -0.068 & 0.077 \\
\hline Dry matter & $-0.815^{*}$ & 0.018 & 0.068 & 0.272 & 0.124 \\
\hline Eigenvalue & 6.428 & 4.038 & 2.870 & 1.885 & 1.261 \\
\hline Proportion (\%) & 33.83 & 21.26 & 15.11 & 9.92 & 6.64 \\
\hline Cumulative (\%) & 33.83 & 55.09 & 70.19 & 80.11 & 86.75 \\
\hline
\end{tabular}

${ }^{1}$ Values estimated by principal factor analysis after Varimax rotation of extracted PCAs

* Variables with loading vectors higher than 0.50 were considered to load on specific PCA.

As shown in Figure 4, the first 2 components of PCA explain 55.1\% of the total variation. Further analysis of the data reveals the variable loadings on PC1 were related to organic acids, such as LA, AA, BA, PA or fermentation characteristics such as $\mathrm{NH}_{3}-\mathrm{N}$, or microbiological composition such as LAB and yeast count (after AE), or DM and DM loss. PC1 had an eigenvalue of 6.428 and explained $33.83 \%$ of the total variability. While the $\mathrm{CO}_{2}$, pH (after AE), WSC, aerobic stability, and yeast count (after AE) loaded on PC2; yeast, DM loss, $\mathrm{pH}$, and mould count (after AE) loaded on PC3 and explained $21.26 \%$ and $15.11 \%$ of the total variability, respectively. PC4 was characterized by LAB, and mould count and explained $9.92 \%$ of the total variability with an eigenvalue of 1.885 . The last component, PC5, was characterized by NH3-N and $\mathrm{pH}$ explaining $6.64 \%$ of the total variability with an eigenvalue of 1.261 .

$16 \mathrm{~S}$ rRNA sequencing was performed to identify the microbial communities in the alfalfa silages systematically. As shown in Table 3, most of the bacteria were detected in alfalfa silage treated with different doses of kefir source. Similarly, as shown in Figure 5, the phylogenic tree, used to estimate the relationship among various species based on genetic distances, clearly reflected the variation of the microbial community.

Table 3. 16SrRNA sequences isolated from ensiling alfalfa treated with different kefir source.

\begin{tabular}{lll}
\hline Treatments & Silo opening & After $\mathbf{7}$ d of Aerobic exposure \\
\hline CON & Lactobacillus brevis & Enterococcus gallinarum, \\
\hline
\end{tabular}




\begin{tabular}{lll}
\hline & & $\begin{array}{l}\text { Enterococcus casseliflavus, } \\
\text { Weissella paramesenteroides }\end{array}$ \\
\hline CK1 & $\begin{array}{l}\text { Pediococcus pentosaceus, } \\
\text { Enterococcus faecium }\end{array}$ & $\begin{array}{l}\text { Lactobacillus plantarum, } \\
\text { Enterococcus faecalis }\end{array}$ \\
\hline CK2 & $\begin{array}{l}\text { Pediococcus pentosaceus, } \\
\text { Enterococcus faecium }\end{array}$ & Bacillus sp., Enterococcus faecalis \\
\hline CK3 & Enterococcus faecium & $\begin{array}{l}\text { Lactobacillus plantarum, } \\
\text { Lactobacillus brevis }\end{array}$ \\
\hline HK1 & Lactobacillus brevis, \\
Enterococcus faecium & $\begin{array}{l}\text { Lactobacillus plantarum, } \\
\text { Lactobacillus brevis }\end{array}$ \\
\hline HK2 & Pediococcus pentosaceus, & $\begin{array}{l}\text { Weissella paramesenteroides, } \\
\text { Enterococcus faecium }\end{array}$ \\
\hline
\end{tabular}

CON: Control, CK: commercial kefir, HK: homemade kefir, HK1: 5.0 log cfu g-1; HK2: $5.7 \log$ cfu g$^{-1}$, HK3: $6.0 \log$ cfu g-1 $^{-1}$ CK1: $5.0 \log _{\text {cfu g-1 }}$,CK2: $5.7 \log$ cfu g-1 $^{-1}$, CK3: $6.0 \log$ cfu g-1 $^{-1}$
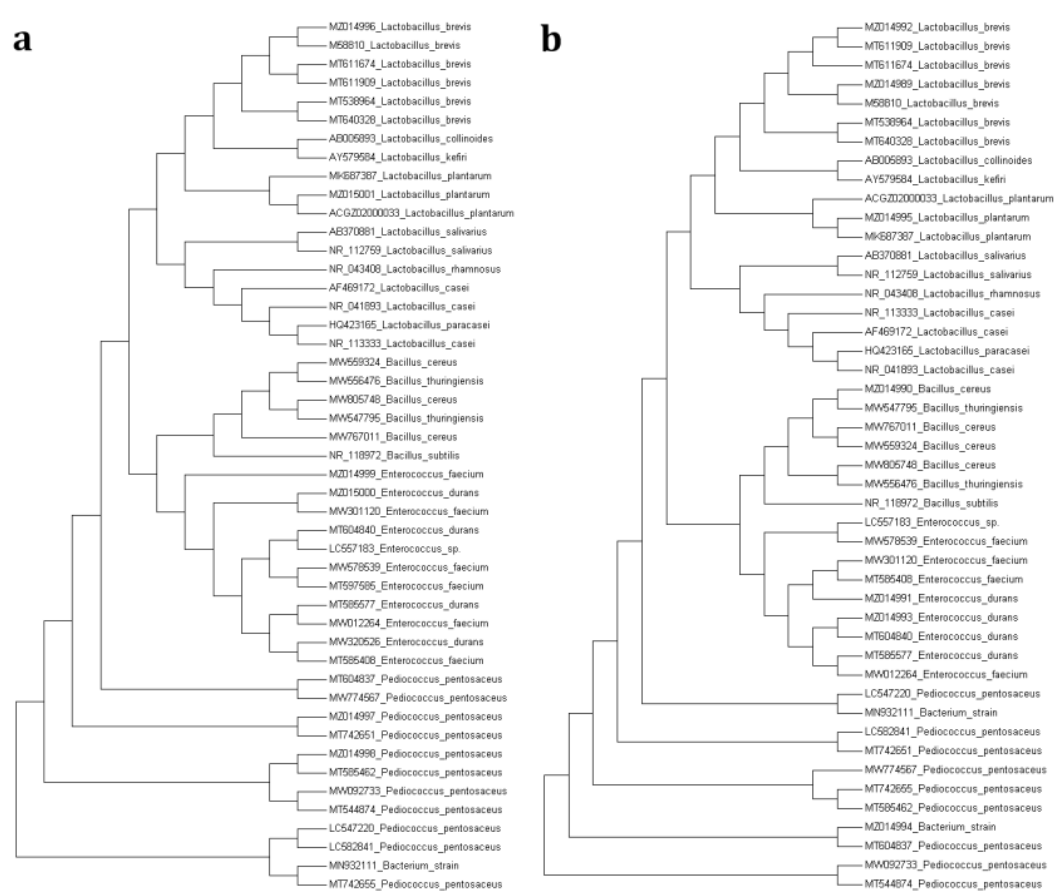

Figure 5. The phylogenic tree of bacterial community is estimated using the NJ method (Kimura 2) that retrieved sequences provided by the NCBI GenBank database (MZ014989- MZ015001 from this study) (https://www.ncbi.nlm.nih.gov/). a: commercial, b: homemade kefir.

$16 \mathrm{~S}$ rRNA sequencing was performed to identify the microbial communities in the alfalfa silages systematically. Figure 5 shows the phylogenetic relationship between the alfalfa silage treated with different doses of kefir sources. Furthermore, the predominant bacterial species isolated at silo opening and after aerobic exposure were summarized in Table 3. $16 \mathrm{~S}$ rRNA sequence analysis indicate that while Enterococcus faecium, Pediococcus pentosaceous, and L. brevis were dominant bacterial species among the treated groups at silo opening; Lactobacillus plantarum and L. brevis became dominant bacterial species after $7 \mathrm{~d}$ of AE.

\section{Discussion}

The present study was designed to determine fermentation quality and microbial community composition of alfalfa silage treated with different kefir sources and to find 
the most suitable dosage of use. Prior studies have noted the importance of an adequate substrate for LAB, DM, and WSC content to produce stable silages [20,21]. The DM content of wilted alfalfa (304.6 g/ $\mathrm{kg} \mathrm{FW)} \mathrm{and} \mathrm{LAB} \mathrm{concentration} \mathrm{(5.30} \mathrm{log} \mathrm{cfu} \mathrm{g-1)} \mathrm{before} \mathrm{en-}$ siling were consistent with the previous studies AOAC. However, the WSC of pre-ensiled material (15.45 $\mathrm{g} \mathrm{kg}^{-1} \mathrm{DM}$ ) was not adequate, considering the recommendation of $50 \mathrm{~g} \mathrm{~kg}^{-1} \mathrm{DM}$ as a minimum required to ensure good fermentation during ensiling [1].

The major limitation of this study is the low WSC content $\left(15.45 \mathrm{~g} \mathrm{~kg}^{-1} \mathrm{DM}\right)$ of wilted alfalfa, which had been not sufficient to initiate lactic acid fermentation (Table 1). One of the most used parameters to determine the level of proteolysis in silages is $\mathrm{NH}_{3}-\mathrm{N}$. Not significantly, but numerically, the $\mathrm{NH}_{3}-\mathrm{N}$ concentration of alfalfa silages were decreased both the addition of different kefir sources (Figure 2). Therefore, it seems the Bc capacity of alfalfa plays a more significant role than the proteolysis during fermentation, considering the obtained results of this study. It is a well-known fact that proteolysis could be account for more than half of the total $\mathrm{N}$ in alfalfa silage during fermentation and may result in efficient $\mathrm{N}$ utilization by ruminants [22]. Besides, it is widely acknowledged that different LAB strains alone or combined with fibrolytic enzymes, sugar source, or organic acid can be used as additives to produce good quality alfalfa silage due to high Bc and low WSC concentration $[23,24]$. While there is limited information on proteolysis and $\mathrm{NH}_{3}-\mathrm{N}$ formation of kefir treated forage, in our study, the treatment with different kefir source and their various doses conserved more LA (HK produce more LA with an increasing application rate), and reduced $\mathrm{NH}_{3}-\mathrm{N}$ concentration.

Wang et al. [25] stated that one major factor that affects the extent of fermentation is silage $\mathrm{pH}$. The current study found that kefir sources cannot be reduced forages' $\mathrm{pH}$ (all above 5.0) to desired level alone when the initial WSC of forage was inadequate (Table 1). A possible explanation for these results may be the lack of adequate LAB growth in alfalfa silage by accelerating LA production to decrease $\mathrm{pH}$ during the fermentation. Prior studies that have noted the importance of ensiling of legume forages with high WSC sources to produce more organic acids and obtain better fermentation quality are confirmed our results [26,27].

The LAB count was higher in treated silages than in the control silage except for HK with an application rate of $5.0 \log \mathrm{cfu} \mathrm{g}^{-1}(\mathrm{P}<0.01$, Figure 1$)$. On the other hand, these results were not confirmed by silage $\mathrm{pH}$ due to the low WSC content of alfalfa. It may be explained by the fact that yeast could be used LA and WSC residue as substrates at the initial fermentation stage, which confirmed by DM loss [28,29].

As previously stated by Kleinschmit and Kung [30], LA/AA ratio could be used as an indicator of an effective homolactic acid fermentation. In general, the study found a tendency for an increasing LA/AA ratio when the application rate was greater than $5 \log$ cfu g-1 which means HK serves mainly homolactic characteristics whereas CK serves mainly heterolactic (Figure 2).

Previous research has shown that DM loss reflects the nutritive value and fermentation quality of silage [31,32]. There were no differences in DM contents between alfalfa silages treated with different kefir sources $(P>0.05)$. However, the lower DM loss was

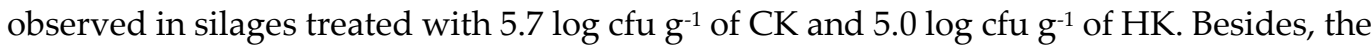
silages treated with $\log 5.7 \mathrm{cfu} \mathrm{g}^{-1}$ of CK had the highest WSC content compared to other silages. As mentioned in the literature review, the amount of DM loss related to fermentation can vary depending on the dominant microbial species and fermented substrates types [31]. The homolactic LAB found in kefir's microbial flora must be played an important role at these application rates to reduce DM loss by limiting plant respiration and undesirable microbial growth. A similar result was also found when chemical additives or homolactic LAB were used as silage additives [33]. Also, a tendency to increase DM loss with an increased application rate of HK was detected in this study. It may be related to dynamic change in microbial community towards heterofermentative characteristics.

Prior studies that have noted the importance of aerobic stability due to its potential cause of DM loss and lead to health risks in animal and humans in terms of mycotoxins 
produced from undesirable microorganisms [7,34]. A number of factors may influence the aerobic stability of silages, such as the size of the LAB population, the composition of inoculants, organic acid concentration, and WSC content of ensiling material [7]. In this study, the highest aerobic stability was observed in CK with an application rate of $5.7 \mathrm{log}$ $\mathrm{cfu} \mathrm{g}^{-1}$ according to the indirect measurement of aerobic deterioration (Figure 3). On the other hand, the addition of CK with an application dose of $5.0 \log _{\text {cfu g-1 }}{ }^{-1}$ and HK with an application dose greater than $5.0 \mathrm{log} \mathrm{cfu} \mathrm{g}^{-1}$ prevent mould formation and inhibit yeast counts in silages suggesting that it improve aerobic stability. A possible explanation for this might be that metabolites produced from LAB, such as acetic acid, 1, 2-propanediol, and ethanol which improve aerobic stability $[2,34]$. Another possible explanation for this is that antimicrobial substances originated from alfalfa silages, e.g., saponin, during the fermentation process possess antimicrobial activity against bacteria and yeast, such as Bacillus subtilis, Candida albicans, and S. cerevisiae [35].

The five silage quality components were related to organic acids, and thus, PC1 can be considered an organic acid-type factor. Surprisingly, a positive relationship was found between aerobic stability, pH (after AE), WSC and yeast count (after AE). This finding was unexpected and suggested that the addition of kefir improves the aerobic stability of silages even the initial WSC content was inadequate via its antimicrobial effect on yeast and mould formation (PC2, Tablo 2). The PC3 confirms that DM loss during ensiling is possibly related to the metabolism of yeasts, which utilizes WSC and produces ethanol [25]. The factor analysis may also support the negative relationship between LAB and mould during the fermentation process. Another negative correlation was detected between $\mathrm{NH}_{3}-\mathrm{N}$ and $\mathrm{pH}$ in PC5. In general, therefore, it seems that the $\mathrm{pH}$ of silages is closely related to the remaining acid concentration after the neutralization of organic acids by $\mathrm{NH}_{3}-\mathrm{N}$ in the silo. These results are similar to those reported by Bai et al. [36].

As shown in Table 1 and Figure 2, comparable results were obtained after $45 \mathrm{~d}$ of fermentation for $\mathrm{pH}$ and LA. Many scholars hold the view that lactic acid-producing cocci, e.g., Pediococci, Streptococci, Enterococci, Lactococci, and Leuconostocs, initiate LA fermentation in the early stages of ensiling and then replaced by more acid-tolerant Lactobacilli such as L. plantarum and L. brevis $[2,37,38]$. $16 \mathrm{~S}$ rRNA sequencing was indicated that E. faecium, P. pentosaceous, and L. brevis were dominant bacterial species among the treated groups at silo opening (Table 3). The most obvious finding to emerge from the $16 \mathrm{~S}$ rRNA sequence analysis is that synergetic effects of E. faecium and P. pentosaceous increased LA concentration and decreased $\mathrm{pH}$ value during the initial stages of ensiling. A possible explanation for these results may be the enzymatic hydrolysis of lignocellulosic biomass by the cellulolytic potential of E. faecium during the ensiling process. A similar LA accumulation and $\mathrm{pH}$ decline was also reported by Li et al. [39] for Pennisetum sinese (a kind of tropical perennial grass) silage.

In contrast, the monitored aerobic stability of $\mathrm{CK}$ with an application rate of $5.7 \mathrm{log}$ $\mathrm{cfu} \mathrm{g}^{-1}$ by indirect and direct methods was not confirmed with $16 \mathrm{~S}$ rRNA sequence analysis. A possible explanation of these inconsistent results was mainly related to the growth of undesirable microorganisms, which results in aerobic deterioration. Although the predominant bacterial species were the same in such silage groups, the aerobic stability was different due to different residual WSC, LA, and AA concentrations found in silages.

\section{Conclusions}

This study set out to investigate the impact of alfalfa treated with different kefir sources and their various application doses on fermentation characteristics and aerobic stability. A key finding of the present study was improving the aerobic stability of silages even with the low WSC content with inhibiting proliferation of yeast and mould. Factor analysis clearly shows that the antimicrobial activity of kefir has an inhibitory effect on yeast count during aerobic exposure. Considerably more work will need to be done to determine the effects of kefir with an adequate level of carbohydrate sources. 


\begin{abstract}
Author Contributions: Conceptualization, F.K. and S.E.; methodology, F.K., S.E., E.Ö.Ü and R.I.; software, S.E. and R. I.; validation, B.O., E.Ö.Ü and R.I.; formal analysis, B.O., E.Ö.Ü. and R.I.; investigation, F.K. and S.E.; data curation, E.Ö.Ü. and F.K.; writing-original draft preparation, S.E. and F.K.; writing - review and editing, S.E., F.K., E.Ö.Ü. and R.I.; visualization, S.E. and R.I. ; supervision, F.K. All authors have read and agreed to the published version of the manuscript.
\end{abstract}

Funding: This research received no external funding.

Data Availability Statement: Not applicable.

Conflicts of Interest: The authors declare no conflict of interest.

\title{
References
}

1. Yuan, X.; Wen, A.; Dong, Z.; Desta, S. T. and Shao, T. 2017. Effects of formic acid and potassium diformate on the fermentation quality, chemical composition and aerobic stability of alfalfa silage. Grass and Forage Science 72(4): 833-839. https://doi.org/10.1111/gfs.12296

2. Jiang, D.; Li, B.; Zheng, M.; Niu, D.; Zuo S. and Xu, C. 2020. Effects of Pediococcus pentosaceus on fermentation, aerobic stability and microbial communities during ensiling and aerobic spoilage of total mixed ration silage containing alfalfa (Medicago sativa L.). Grassland Science 66:215-224. https://doi.org/10.1111/grs.12272

3. McGarvey, J. A.; Franco, R. B.; Palumbo, J. D.; Hnasko, R.; Stanker, L. and Mitloehner, F. M. 2013. Bacterial population dynamics during the ensiling of Medicago sativa (alfalfa) and subsequent exposure to air. Journal of Applied Microbiology 114(6): 1661-1670. https://doi.org/10.1111/jam.12179

4. Zhang, Q.; Yu, Z.; Wang, X. and Tian, J. 2018. Effects of inoculants and environmental temperature on fermentation quality and bacterial diversity of alfalfa silage. Animal Science Journal 89(8):1085-1092. https://doi.org/10.1111/asj.12961

5. Guo, X. S.; Bai, J.; Li, F. H.; Xu, D. M.; Zhang, Y. X.; Bu, D. P. and Zhao, L. S. 2020. Effects of malate, citrate, succinate and fumarate on fermentation, chemical composition, aerobic stability and digestibility of alfalfa silage. Animal Feed Science and Technology 268:114604. https://doi.org/10.1016/j.anifeedsci.2020.114604

6. Zhao, S. S.; Wang, Y. P.; Yang, F. Y.; Wang, Y. and Zhang, H. 2020. Screening a Lactobacillus plantarum strain for good adaption in alfalfa ensiling and demonstrating its improvement of alfalfa silage quality. Journal of Applied Microbiology 129(2):233-242. https://doi.org/10.1111/jam.14604

7. Tao, L.; Zhou, H.; Zhang, N.; Si, B.; Tu, Y; Ma, T. and Diao, Q. 2017. Effects of different source additives and wilt conditions on the $\mathrm{pH}$ value, aerobic stability, and carbohydrate and protein fractions of alfalfa silage. Animal Science Journal 88(1): 99-106. https://doi.org/10.1111/asj.12599

8. Schnürer, J. and Jonsson, A. 2011. Pichia anomala J121: a 30-year overnight near success biopreservation story. Antonie van Leeuwenhoek 99: 5-12. https://doi.org/10.1007/s10482-010-9509-2

9. Chen, R.; Yang, S.; Zhang, L. and Zhou, Y. J. 2020. Advanced Strategies for Production of Natural Products in Yeast. iScience 23 (3): 100879 https://doi.org/10.1016/j.isci.2020.100879.

10. Anonymous. 1986. The analysis of agricultural material. Reference Book, London, United Kingdom, 427-428 pp.

11. Playne, M. J. and Mc Donald, P. 1966. The buffering constituent of herbage and of silage. Journal of the Science of Food and Agriculture 17:264-268. https://doi.org/10.1002/jsfa.2740170609

12. Ulger, I.; Buyukkılıc Beyzi, S.; Kaliber, M. and Konca, Y. 2020. Chemical, nutritive, fermentation profile and gas production of citrus pulp silages, alone or combined with maize silage. South African Journal of Animal Science 50(1):161-169. https://doi.org/10.4314/sajas.v50i1.17

13. Koc, F. and Coskuntuna, L. 2003. The comparison of the two different methods on the determination of organic acids in silage fodders. Journal of Animal Production 44(2):37-47.

14. Seale, D. R.; Pahlow, G.; Spoelstra, S. F.; Lindgren, S.; Dellaglio, F. and Lowe, J. F. 1990. Methods for the microbiological analysis of silage. p:147. In: Proceeding of the Eurobac Conference, Uppsala.

15. Asbell P. and Stenson S. 1982. Ulcerative keratitis. Survey of 30 years' laboratory experience. Arch Ophthalmol 100:77-80.

16. Liu, B.; Huan, H.; Gu, H.; Xu, N.; Shen, Q. and Ding, C. 2019. Dynamics of a microbial community during ensiling and upon aerobic exposure in lactic acid bacteria inoculation- treated and untreated barley silages. Bioresource Technol. 273: 212-219.

17. Beasley, S. S. and Saris P. E. J. 2004. Nisin-producing Lactococcus lactis strains from human milk. Appl. Environ. Microbiol. 70: 5051- 5053.

18. Kumar, S.; Stecher, G. and Tamura, K. 2016. MEGA7: Molecular Evolutionary Genetics Analysis Version 7.0 for Bigger Datasets. Mol Biol Evol 33: 1870-1874. https://doi.org/10.1093/molbev/msw054

19. SAS. 2004. SAS/STAT® User's Guide: Statistics (version 9.1). SAS Institute Inc. Guide. Cary, NC.

20. Liu, Q. H.; Yang, F. Y.; Zhang, J. G. and Shao, T. 2014. Characteristics of Lactobacillus parafarraginis ZH1 and its role in improving the aerobic stability of silages. Journal of Applied Microbiology 117:405-416. https://doi.org/10.1111/jam.12530

21. Lynch, J. P.; Jin, L.; Lara, E. C.; Baah, J. and Beauchemin, K. A. 2014. The effect of exogenous fibrolytic enzymes and a ferulic acid esterase-producing inoculant on the fibre degradability, chemical composition and conservation characteristics of alfalfa silage. Animal Feed Science and Technology 193:21-31. https://doi.org/10.1016/j.anifeedsci.2014.03.013 
22. Li, P.; Ji, S.; Hou, C.; Tang, H.; Wang, Q. and Shen, Y. 2016. Effects of chemical additives on the fermentation quality and N distribution of alfalfa silage in south of China. Animal Science Journal 87(12):1472-1479. https://doi.org/10.1111/asj.12600

23. Muck, R. E.; Nadeau, E. M. G.; McAllister, T. A.; Contreras-Govea, F. E.; Santos, M. C. and Kung, L. Jr. 2018. Silage review: Recent advances and future uses of silage additives. Journal of Dairy Science 101(5):3980-4000. https://doi.org/10.3168/jds.2017-13839

24. Wang, B. and Yu, Z. 2020. Effects of moisture content and additives on the ensiling quality and vitamins changes of alfalfa silage with or without rain damage. Animal Science Journal 91(1): e13379. https://doi.org/10.1111/asj.13379

25. Wang, C.; He, L.; Xing, Y.; Zhou, W.; Yang, F.; Chen, X. and Zhang, Q. 2019. Fermentation quality and microbial community of alfalfa and stylo silage mixed with Moringa oleifera leaves. Bioresource Technology 284:240-247. https://doi.org/10.1016/j.biortech.2019.03.129

26. Zhang, Q.; Zhao, M.; Wang, X.; Yu, Z. and Na, R. 2017. Ensiling alfalfa with whole crop corn improves the silage quality and in vitro digestibility of the silage mixtures. Grassland Science 63(4):211-217. https://doi.org/10.1111/grs.12168

27. Ni, K.; Zhao, J.; Zhu, B.; Su, R.; Pan, Y.; Ma, J.; Zhou, G.; Tao, Y.; Liu, X. and Zhong, J. 2018. Assessing the fermentation quality and microbial community of the mixed silage of forage soybean with crop corn or sorghum. Bioresource Technology, 265, 563-567. https://doi.org/10.1016/j.biortech.2018.05.097

28. Ávila, C. L. S.; Carvalho, B. F.; Pinto, J. C.; Duarte, W. F. and Schwan, R. F. 2014. The use of Lactobacillus species as starter cultures for enhancing the quality of sugar cane silage. Journal of Dairy Science 97(2):940-951. https://doi.org/10.3168/jds.2013-6987

29. Bai, J.; Xu, D.; Xie, D.; Wang, M.; Li, Z. and Guo, X. 2020. Effects of antibacterial peptide-producing Bacillus subtilis and Lactobacillus buchneri on fermentation, aerobic stability, and microbial community of alfalfa silage. Bioresource Technology 315:123881. https://doi.org/10.1016/j.biortech.2020.123881

30. Kleinschmit, D.H.; Kung, L. Jr. 2006. The effects of Lactobacillus buchneri 40788 and Pediococcus pentosaceus R1094 on the fermentation of corn silage. Journal of Dairy Science 89: 3999-4004. https://doi.org/10.3168/jds.S0022-0302(06)72443-2

31. Borreani, G.; Tabacco, E.; Schmidt, R. J.; Holmes, B.J. and Muck, R.E. 2018. Silage review: factors affecting dry matter and quality losses in silages. Journal of Dairy Science 101:3952-3979. https://doi.org/10.3168/jds.2017-13837

32. Guo, L.; Yao, D.; Li, D.; Lin, Y.; Bureenok, S.; Ni, K. And Yang, F. 2020. Effects of lactic acid bacteria isolated from rumen fluid and feces of dairy cows on fermentation quality, microbial community, and in vitro digestibility of alfalfa silage. Frontiers in Microbiology 10:2998. https://doi.org/10.3389/fmicb.2019.02998

33. Auerbach, H. and Nadeau, E. 2020. Effects of additive type on fermentation and aerobic stability and its interaction with air exposure on silage nutritive value. Agronomy 10(9):1229. https://doi.org/10.3390/agronomy10091229

34. Guo, X. S.; Undersander, D. J. and Combs, D. K. 2013. Effect of Lactobacillus inoculants and forage dry matter on the fermentation and aerobic stability of ensiled mixed-crop tall fescue and meadow fescue. Journal of Dairy Science 96:1735-1744. https://doi.org/10.3168/jds.2045-5786

35. $\mathrm{Wu}, \mathrm{B}$. and Nishino, N. 2015. Identification and isolation of Lactobacillus fructivorans from wilted alfalfa silage with and without molasses. Journal of Applied Microbiology 120:543-551. https://doi.org/10.1111/jam.13031

36. Bai, J.; Ding, Z.; Ke, W.; Xu, D.; Wang, M.; Huang, W.; Zhang, Y.; Liu, F. And Guo, X. 2021. Different lactic acid bacteria and their combinations regulated the fermentation process of ensiled alfalfa: ensiling characteristics, dynamics of bacterial community and their functional shifts. Microbial Biotechnology. https://doi.org/10.1111/1751-7915.13785 (in press).

37. Ni, K.; Wang, F.; Zhu, B.; Yang, J.; Zhou, G.; Pan, Y.; Tao, Y. and Zhong, J. 2017. Effects of lactic acid bacteria and molas ses additives on the microbial community and fermentation quality of soybean silage. Bioresource Technology 238: 706-715. https://doi.org/10.1016/j.biortech.2017.04.055

38. Xu, D. M.; Ke, W. C.; Zhang, P.; Li, F. H. and Guo, X. S. 2018. Characteristics of Pediococcus pentosaceus Q6 isolated from Elymus nutans growing on the Tibetan Plateau and its application for silage preparation at low temperature. Journal of Applied Microbiology, 126(1): 40-48.

39. Li, J.; Yuan, X.; Desta, S. T.; Dong, Z.; Mugabe, W. and Shao, T. 2018. Characterization of Enterococcus faecalis JF85 and Enterococcus faecium Y83 isolated from Tibetan yak (Bos grunniens) for ensiling Pennisetum sinese. Bioresource Technology 257: 76-83. https://doi.org/10.1016/j.biortech.2018.02.070 